\title{
Evaluation of the protective capacity of Toxocara canis embryonated egg antigen in rabbits
}

\author{
S. M. Aboel Hadid \\ Department of Parasitology Faculty of Veterinary Medicine, Beni-Suef University
}

\begin{abstract}
Toxocariasis is a disease of unspecific clinical manifestations in human beings and some animals forming a condition known as visceral larva migerans. Effective Toxocara canis (T. canis) control should destroy the dormant hypobiotic larvae in the tissues of the reservoir hosts. Embyonated egg antigen is intended to be evaluated in rabbits where15 New Zealand rabbits were divided into 3 groups; immunized group that injected with three doses of $T$. canis egg antigen (First dose with complete Freund's and two successive doses with incomplete Freund's adjuvant); control infected group and adjuvant control group. At $30^{\text {th }}$ day from the beginning of the experiment, all groups were infected with $10,000 T$. canis embryonated egg. Blood samples were collected periodically for measuring antibodies titer by ELISA. Postmortem and histopathological investigations were done. The efficacy of egg antigen protective immunity was evaluated by; the positive antibody titer, retention of larvae in the liver, hepatic eosinophilic granuloma formation, number of the milky spots on the liver surface and lung resistance to the infection. These parameters were detected obviously in the immunized group than the non immunized ones. Consequently, production of this product is recommended where its preparation is simple, easy, fast and economic and may be used as role of vaccine program against the parasite infection in the susceptible hosts.
\end{abstract}

Toxocariasis is one of the parasitic diseases which constitute a public health problem allover the world (Agudelo et al., 1990; Morales et al., 2002). Toxocariasis caused by the larvae of nematodal helminth Toxocara canis (T. canis) which frequently present in dogs intestine (Schantz and Glickman, 1983). After ingestion of infective eggs, the larval stage freed and migrated through the soft tissues of the body of many paratenic hosts; mice, rabbits, pigs and human (Abo-shehada and Herbert, 1984; Helwigh et al., 1999; Sommerfelt et al., 2004). In the paratenic hosts, the migrated larvae may lead to ocular or visceral larval migrans syndrome (Gillespie et al., 1993). This migration produced tissue pathological changes whenever the larvae disseminated throughout the body, where they could live either encapsulated and/or free in the brain for long periods (Glickman and Summers, 1983). The lesions in liver represented by small white spots covering the surface; in lung had small areas of consolidation and hemorrhagic patches; also the necrotic foci and eosinophilic infiltration were recorded (Sommerfelt, et al., 2004; Taira, et al., 2004; Azizi et al., 2007)
The effective control of this disease should destroy the dormant hypobiotic larvae in the tissues of the paratenic hosts. Ongoing administration of anthelmintics was neither a practical nor a reliable solution. In contrary, immunization of this host is long lasting and more potent (Barriga, 1988). Immunization of mice with Toxocara larval extracts or metabolic (excretory/secretory) product showed a certain level of immunoprotection and so effective anti T. canis vaccine could be expected in the future (Dvorozankova et al., 2002; El-Zawawy, 2003).

Vaccine efficacy against toxocariasis must be evaluated by; the positive antibody titer, retention of larvae in the liver, hepatic eosinophilic granuloma formation and number of the milky spots on the liver surface and lastly lung resistance to the infection (Sugan and Oshima, 1983; Abo-Shehada and Herbert, 1989; Parsons and Grieve, 1990; Abo-Shehada et al., 1991; Serrano et al. ,2001; Cuellar et al., 2001; El-Zawawy, 2003; Frontera et al., 2003).

So, the present work aimed to immunize rabbits using infective stage (egg containing second larval stage) of $T$. canis and evaluate this vaccine.

\footnotetext{
* Corresponding author. Tel.: +20 0108525674 ;

Fax: +20 0822327982

E-mail address: hadid@bsu.edu.eg

(Shawky M. Aboel Hadid)
} 


\section{Materials and methods}

Preparation of the infective and immunized materials. Toxocara canis adult worms were collected from naturally infected puppies of age (2 weeks-2months). The animals were transferred to Parasitology department, Faculty of Veterinary Medicine, Beni-Suef University. These puppies were examined coprologically to show that infected by $T$. canis or not. The infected puppies were treated to expel the worms. These worms were washed by saline then the gravid female worms were incubated in $(0.15 \mathrm{M} \mathrm{NaCL})$ at $37 \mathrm{C}^{\mathrm{o}}$ for $24-72 \mathrm{hs}$ to induce eggs laying in which daily collection of worms eggs was occurred, (Barriga and Omar, 1992). Egg embryonation was carried out through its spreading as a single layer in Petri dishes half filled with formal saline, $1 \%$ then was incubated at $28 \mathrm{C}^{\mathrm{o}}$ for 30 days and every 2 days the solution was changed and aerated (Nunes et al., 1997). The infective stage (egg containing second stage larvae, embryonated eggs) were divided into 2 parts, one as infective materials were stored till used and the other part for antigen preparation. The later carried out in which the embryonated eggs were washed several times with 0.01 M PBS ( $\mathrm{pH} 7.4)$ by centrifugation at 1500 r.p.m. for 10 minutes to remove the formal saline remnant. Then mixing with an equal volume of the same solution was done and homogenized at $6000 \mathrm{rpm}$ for 5 minutes in ice bath. The homogenized sample was sonicated. The suspension was subjected to high speed centrifugation $14,000 \mathrm{rpm}$ for 30 minutes at $4^{\circ} \mathrm{C}$. The supernatant containing soluble antigenic materials was separated and stored at $-20^{\circ} \mathrm{C}$ in $1 \mathrm{ml}$ plastic vial till used as egg antigen according to (Sabry, 1999). The protein contents of antigenic material were measured using the modified Lowry's Assay, (1951).

Rabbits. Fifteen male of 1.5-2 kg New Zealand rabbits, were divided into 3 groups (five in each) Group (A). Immunized with $T$. canis antigen (immunized T. canis group).Group (B). injected with Adjuvant alone as control group (adjuvant control group).Group (C). infected with $T$. canis eggs as control positive T. canis group (control infected T. canis group).

\section{Experimental design.}

Immunization protocol. It was performed according to the protocol described by (Langley and Hillyer, 1989).

In group (A), rabbits were vaccinated against $T$. canis infection by the egg antigen with Freund's adjuvant in ratio of 1:1 (injected S/C in two sites above the shoulder at three doses), the 1st injection at zero day was $600 \mu \mathrm{g}$ protein of the prepared antigen (which were obtained from $600 \mu \mathrm{l}$ of the soluble extract) per animal with Freund's complete adjuvant. The rabbits then injected with $400 \mu \mathrm{g}$ protein per animal with Freund's incomplete adjuvant at 14 and 21 day from the beginning of the experiment. In group (B) the animals were injected with a dose of Freund's complete adjuvant alone at zero day $\mathrm{S} / \mathrm{C}$ in two sites above the shoulder, then the second and third doses were Freund's incomplete adjuvant at 14 and 21 day from the beginning of the experiment respectively. Group $\mathrm{C}$ were lifted with out any injection.

Infection protocol. The groups (A, B and C) were infected after 30 days from the beginning of the experiment with 10,000 embryonated $T$. canis eggs (infective stage) orally using stomach tube.

Periods of blood collection and preparation. Blood collected at zero day, 14 and 21 day post immunization and 14, 21, 30, 45 and 60 days post infection (p.i.). The sera were isolated from blood samples and stored till used.

Antibodies detection using Enzyme linked immunosorbant assay (ELISA). ELSA has been developed to detect antibodies titer was carried out according to Moralez et al., (2002). Briefly, ELISA plate was coated with $100 \mu \mathrm{l} /$ well of egg antigen at the concentration of $20 \mu \mathrm{g}$ protein/ ml coating buffer after checker board titration which applied to determine the optimal antigen concentration and serum dilution. The plates were incubated overnight at $4^{\circ} \mathrm{C}$ then washed three times with PBS Tween 20 and blocked with the blocking buffer $(200 \mu 1$ / well), incubated at room temperature for $2 \mathrm{~h}$. The plates were washed, $100 \mu \mathrm{l} /$ well of 1:100 diluted serum samples from infected rabbits and negative sera were added and the plates was incubated for $2 \mathrm{~h}$ at $37^{\circ} \mathrm{C}$ with shaking. Washing occurred and $100 \mu 1 /$ well of anti-rabbit IgG alkaline phosphatase conjugate was added and incubated one hour at $37^{\circ} \mathrm{C}$ with shaking then were washed. $50 \mu \mathrm{l} /$ well of substrate solution were added to all wells and the plates were incubated for 30 minutes at $37^{\circ} \mathrm{C} .50 \mu \mathrm{l} /$ well of $1 \mathrm{~N} \mathrm{Na} \mathrm{OH}$ were added for stopping the reaction. The optical densities (O. D) were read at $405 \mathrm{~nm}$ with a micro-ELISA reader system. The sera were considered to be positive when the absorbance values were as or more than the cut off value (the cut off= double fold of the mean negative sera) according to (Iacona et al., 1980). 
Table (1): Mean concentration of antibodies to the different groups using ELISA.

\begin{tabular}{lccc}
\hline \multirow{2}{*}{ Time } & \multicolumn{3}{c}{ Group } \\
\cline { 2 - 4 } & $\begin{array}{c}\text { Control positive } \boldsymbol{T} . \\
\text { canis } \text { group }\end{array}$ & $\begin{array}{c}\text { Immunized } \boldsymbol{T} \text {. } \\
\text { canis } \text { group }\end{array}$ & $\begin{array}{c}\text { Adjuvant } \boldsymbol{T} \text {. canis } \\
\text { group }\end{array}$ \\
\hline Zero day & 0.142 & 0.153 & 0.139 \\
14 days post immunization & 0.154 & 0.432 & 0.225 \\
21 days post immunization & 0.157 & 0.633 & 0.252 \\
15 days p.i. & 0.280 & 0.728 & 0.375 \\
$\mathbf{2 1}$ days p.i. & 0.395 & 0.835 & 0.413 \\
30 days p.i. & 0.463 & 0.896 & 0.478 \\
$\mathbf{4 5}$ days p.i. & 0.476 & 0.980 & 0.479 \\
60 days p.i. & 0.482 & 0.986 & 0.484 \\
\hline
\end{tabular}

These readings were the mean and the cut off value (double fold of negative one) was $(0.305 \mathrm{~nm})$.

P.i. $=$ Post-infection

Postmortem and Histopathological pictures. All rabbits slaughtered at 60 day p.i. The internal organs mainly liver, lung, kidney and spleen were examined macroscopically. For the microscopic examination; small parts were fixed in formalin $10 \%$ for at least 24 hours before preparation for histopathological study. Paraffin sections, $5 \mu \mathrm{m}$ thick, were prepared by conventional methods then were stained with (H\&E) according to (Bancrroft and Stevens, 1996).

\section{Results \\ Enzyme linked immunosorbant assay} (ELISA) antibodies detection. ELISA was performed on sera of different rabbit groups with $T$. canis embyonated egg antigen at zero days from the experiment beginning, 14 and 21day post immunization then $14,21,30,45$ and 60 day post infection (p.i.). The positively threshold value (considered as double fold of mean negative sera) was at O.D $(0.305 \mathrm{~nm})$. It has been found that in the immunized $T$. canis group; the antibody titer $(0.432 \mathrm{~nm})$ was found at the 14 days post immunization and reached to $(0.633 \mathrm{~nm})$ at 21 days post immunization. The titer increased to $(0.728 \mathrm{~nm})$ at 15 days p.i and then gradually increased to its maximum $(0.980 \mathrm{~nm})$ and $(0.986 \mathrm{~nm})$ at 45 and 60 days p.i. Meanwhile, in the infected control T. canis group; the first positive mean antibody titer $(0.395 \mathrm{~nm})$ was at 21 days p.i. and then increased to reach its peak $(0.482 \mathrm{~nm})$ at 45 and 60 days p.i. Concerning to the adjuvant group, the mean antibody titer $(0.375 \mathrm{~nm})$ appeared at 14 days p.i. and then increased but did not exceed than $(0.484 \mathrm{~nm})$ at the end of the experiment (Table 1).

Postmortem findings and histopathological results. The P.M. findings of the immunized $T$. canis group revealed that, the liver surface had large number of small size necrotic foci (milky spots) plate (1, A, A1). Furthermore, the lungs appeared normally, plate (1A, A2). The microscopic picture of liver tissues showed, clear multi eosinophilic encapsulated granulomatus reaction around retained larvae with giant cell formation, plate (2, I, A and B). The most characteristic finding was the retention of the larvae through the liver, plate (2, I, C). Contrary to these, the microscopic picture of the lung appeared normal without granuloma formation, plate $(2, \mathrm{I}, \mathrm{D})$.

Concerning to, the infected control and adjuvant groups, the hemorrhagic patches in the lung were obviousl, plate (1, B, B2). In addition, the microscopic readings of the lung showed diffuse non encapsulated eosinophilic granuloma, plate (2, II, F). By observing the liver, very few numbers of milky spots were found, plate (1, B, B1). Histopathological findings showed very small number of eosinophilic reaction, plate (2, II, E).

\section{Discussion}

Toxocariasis is a frequent helminthiasis that can cause visceral and ocular damage in humans especially in children. Effective T. canis control should destroy the dormant hypobiotic larvae in the tissues of the reservoir hosts.

Results of ELISA showed that, the immunized $T$. canis group gave higher titer of immunoglobulins in comparison with the infected control and adjuvant groups, in which the titer increased from the 14th day post immunization and then gradually rose with challenge till the end of the experiment. The immunized material sensitized the immune system as the humeral immune response act to increase the immunoglobulines against $T$. canis 

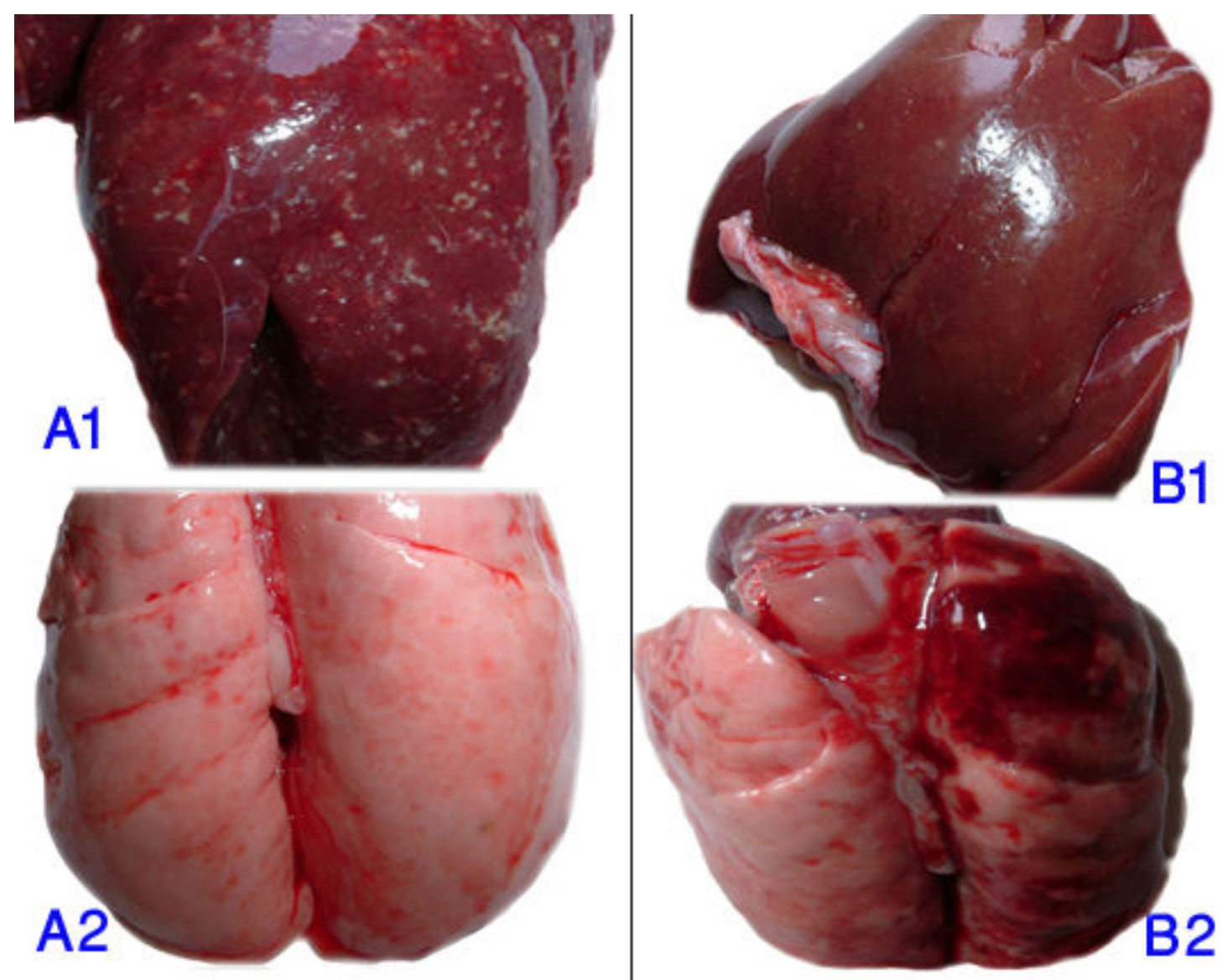

Plate (1): A. Macroscopic pictures of immunized T. canis group.

A1. Liver surface covered with numerous milky spots due to retained larvae.

A1. Lung appears normal.

B. Macroscopic pictures of control positive T. canis group.

B1. Liver surface showed few numbers of milky spots due to healing of the lesion post larval migration.

B2. Lung showed hemorrhagic patches.

infection. These results were consistent with that of Parsons et al., (1993); Cuellar et al., (2001); Fan et al., (2003) whom recorded that the Thelper cells played a key role in the capture of migrating larvae of $T$. canis in the liver. In observing ELISA results of the other groups, no

immunization so the titer was lower than the immunized group. With respect to the gross pictures of livers in the immunized group, marked numerous small sizes necrotic foci (milky spots) were detected due to the larvae migration and retention in the liver tissues. Added to that, the microscopic pictures showed granulomatous reactions around the retained larvae and did not distribute due to the immunization. This picture was absent in the lung and other tissues. Numerous authors found that the larvae of $T$. canis were trapped in the liver parenchyma post challenge (Sugan and Oshima, 1983; Concepcion and Barriga, 1985; Parsons and Grieve, 1990; Abo -Shehada et al., 1991; Parsons et al., 1993) but they worked on mice not rabbits. It's worthy to clarify that; the immune system ability can not destroy $T$.canis larvae. This opinion strengthens by Badley et al., (1987) who cleared that the release of the surface antigens may be important in allowing larvae to evade the host immune response by facilitating the removal of antibodies and eosinophils from the larval surface. Rockey et al., (1983) found that parasites were able to partially evade interaction with eosinophils in culture by shedding their sheaths. Furthermore, Huwer et al., (1989); Lombardi et al., (1990) said that, despite of binding the inflammatory cells however the larvae were able to escape and maintain their infectivity and not damage. Also, 

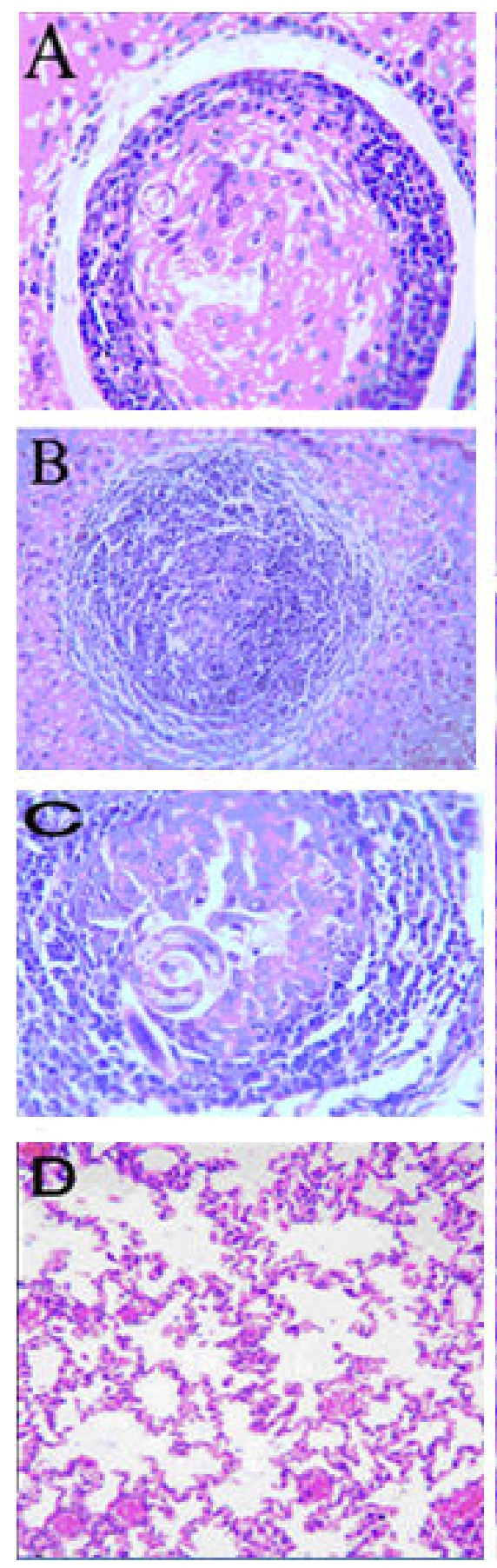

I
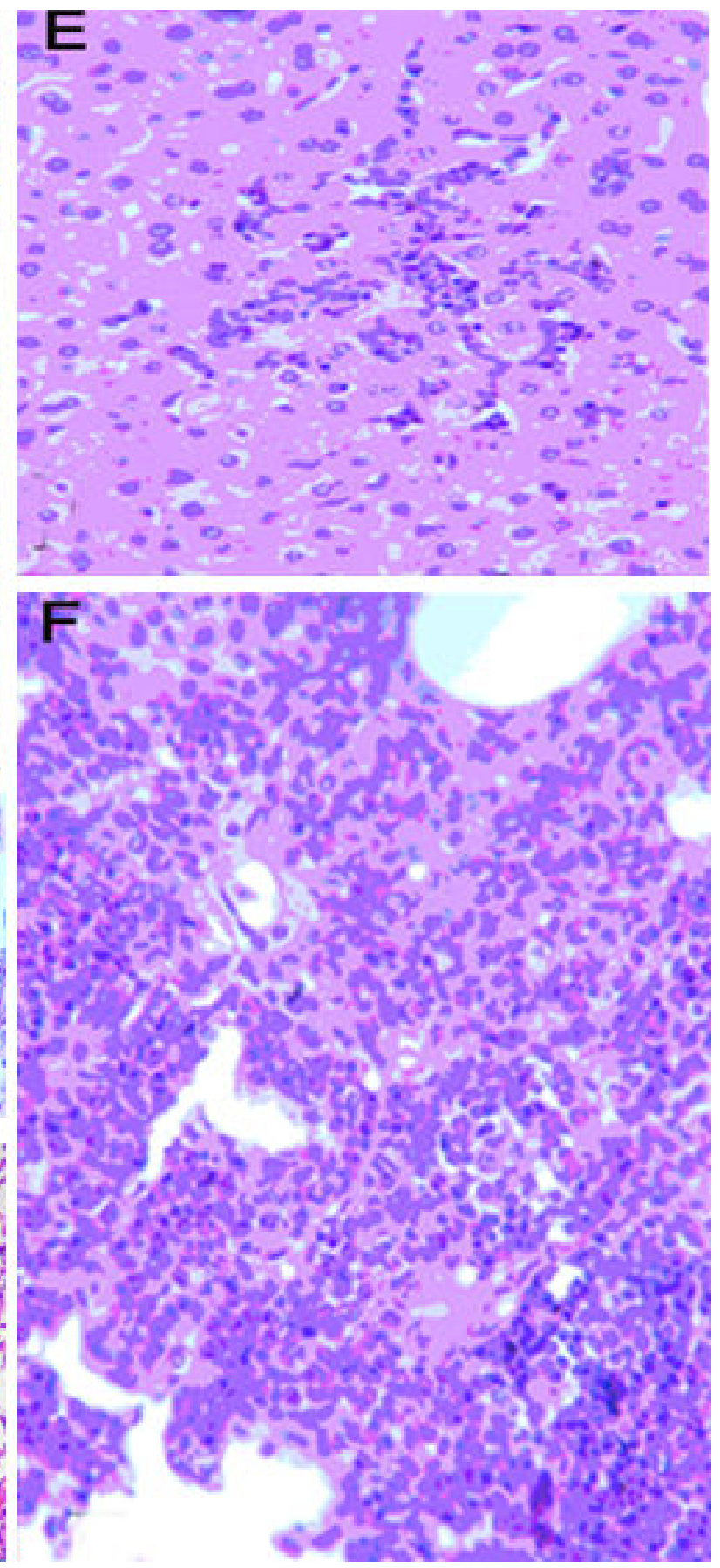

II

Plate (2):

I. Microscopic lesions of immunized Toxocara canis group.

A. Liver tissue showed granulomatus reaction surrounding remnant of cut

Larvae (H\&E .stain X 400).

B. Eosinophilic granulomatus tissue in liver (H\&E .stain X 200).

C. Granulomatus reaction around retained larvae in liver (H\&E .stain X 400).

D. Lung appears normal (H\&E .stain X 400).

II. Microscopic lesions of infected Toxocara canis group.

E. Liver showed Eosinophilic infiltration due to larval migration (H\&E stain X 400).

F. Lung showed diffuse non capsulated granulomatus reaction (H\&E stain X 400). 
El-Zawawy, (2003) reported that T. canis immunized mice revealed intense cellular infiltration with abundance of eosinophils and acceleration in the granulomas formation in their liver sections. On contrary to that, the liver of infected control and adjuvant groups, showed minimal granulomatas but the lung of these groups had many granulomotas due to the larvae migrated from liver to lung causing this lesions. On the other hand, the lung appeared free from any spots due to the immunization which prevent the larvae migration to it. This augmented by Serrano et al., (2001) who stated that, the highest degree of the lung resistance was observed n pigs immunized with $A$. sum eggs, while the reduction of white spots following immunization was less evident. Frontera et al., (2003) detected that the immunized pigs developed humeral immune response (IgG) which was negatively correlated to the number of larvae in the lungs, and positively associated with the liver white spots number. The lung of the infected control and adjuvant groups, showed hemorrhagic batches and these due to the migrating larvae and absence of immune response which developed by immunization. The prepared immunized material (larvated eggs) had a great ability for stimulation of the immune responses in the following categories; the retention of the larvae in the liver, elevated antibody titer, a great ability for granulomatous reaction formation and high resistance in the lung against the migrating larvae. Vaccination against the disease was supported by findings of Nicholas et al., (1984) who showed that mice hyper-immunized with $T$ .canis (E/S antigen) in adjuvant were significantly resistant to infection. Furthermore, Barriga, (1988) said that hyperimmunization with partially purified extracts of $T$.canis larvae induced $(37 \%)$ resistance to a challenge in mice administered the extract alone, and it was (76\%) when administered with lipopolysaccharide adjuvant. Also, the obtained results came in agreement with Abo-Shehada et al., (1991) who determined that using of ultravilot irradiated embryonated eggs gave the best protection against reinfection. Besides, Dvorozankova et al., (2002) reported that E/S was more effective in the protection against larval toxocariasis than somatic antigen. Moreover, EL-Zawawy, (2003) showed that immunization of mice with microwaved embryonated eggs of $T$.canis could induce a significant protection against the challenge. So, vaccine production for control of toxocariasis by using egg antigen may be feasible, where its preparation is simple, easy, fast and economic.

In conclusion, the prepared vaccine showed a high degree of the protection through the retention of the larvae in the liver, marked lung resistance, well distinct granulomas formation in liver and elevated antibodies titer. Consequently, production of this vaccine might be recommended since its preparation is simple, easy, fast and economic.

\section{References}

Abo-Shehada, M. N. and Herbert, I. V. (1984): The migration of larval Toxocara canis in mice. II. Postintestinal migration in primary infections. Vet Parasitol. Dec; 17(1):75-83.

Abo-Shehada, M. N.; Al-Zubaidy, B. A. and Herbert, I. V. (1991): Acquired immunity to Toxocara canis infection in mice. Vet Parasitol. 38(4):289-98.

Agudelo, C.; Villareal, E. and Caceres, E. (1990): Human and dogs Toxocara canis infection in a poor neighborhood in Bogota. Mem. Inst. Oswaldo Cruz, 85: 75 -78 .

Azizi, S.; Oryan, A. ; Sadjjadi, S. M. and Zibaei, M. (2007): Histopathologic changes and larval recovery of Toxocara cati in experimentally infected chickens. Parasitol Res., 102(1):47-52.

Badley, J. E.; Grieve, R. B.; Rockey, J. H. and Glickman, L. T. (1987): Immune-mediated adherence of eosinophils to Toxocara canis infective larvae: the role of excretory-secretory antigens. Parasite Immunol., 9(1):13343.

Bancroft, J. E. and Stevens, A. (1996): Theory and Practice of Histological Techniques. $4^{\text {th }}$ ed. Chukhll Livingstone New York.

Barriga, O. O. (1988): A critical look at the importance, prevalence and control of toxocariasis and the possibilities of immunological control. Vet. Parasitol., 29(2-3):195-234

Barriga, O. O. and Omar, M. H. (1992): Immunity to Toxocara vitulorum repeated infection in a rabbit model. Vet. Immunol. Immunopathol., 33:249-260.

Cuéllar, C.; Fenoy, S.; del-Aula, C. and Guillen , L.(2001): Isotype specific immune resonses in murine experimental toxocariasis. Mem. Inst. Oswaldo Cruz. 96, pp. 549-553.

Concepcion, J. E. and Barriga, O. O. (1985): Transfer of infection-induced immune protection to Toxocara canis in a mouse model. Vet. Immunol. Immunopathol., 9(4):371-82.

Dovrozankova, E.; Borsokova, Z. and Tomasovicova, O. (2002): Immune responses in mice immunized Toxocara canis antigens. Helminthologia, 39(2):59-66.

EL Zawawy, L. A. (2003): Immunization of mice against experimental toxocariasis using microwaved Toxocara canis larvated eggs. J. Med. Res. Inst. (24)4.

Fan, C. K.; Lin, Y. H.; Du, W. Y. and Su, K. E.(2003): Infectivity and pathogenicity of 14-month-cultured embryonated eggs of Toxocara canis in mice. Vet. Parasitol., 113(2):145-55.

Fattah, D. I.; Maizels, R. M.; McLaren, D. J. and Spry C. J.(1986): Toxocara canis: interaction of human blood eosinophils with the infective larvae. Exp. Parasitol., 61(3):421-31.

Frontera, E.; Carrón, A. Serrano, F. J.; Roepstorff, A.; Reina, D. and Navarrete, I. (2003): Some new aspects of 
the pathology, pathogenesis, and aetiology of disseminated lung lesions in slaughter pigs. APMIS, 111(5):531-538.

Gillespie, S.; Dinning, W.; Voller, A. and Crowcroft, N. (1993-a): The spectrum of ocular toxocariasis. Eye, 7: 415 -418 .

Glickman, L. T. and Summers, B. (1983): Experimental Toxocara canis infection in cygonomolgus macaques (Macaca fascicularis). Am. J. Vet. Res., 44 (12): 2347 2354.

Huwer, M.; Sanft, S. and Ahmed, J. S. (1989): Enhancement of neutrophil adherence to Toxocara canis larvae by the $\mathrm{C} 3$ component of complement and IgG antibodies. Zentralbl. Bakteriol. Mikrobiol. Hyg. [A], 270(3):418-423.

Helwigh, A. B.; Lind, P. and Nansen, P. (1999): Visceral larva migrans. Migratory pattern of Toxocara canis infection in pig. Int. J. Parasitol., 29: 559-565.

Iacona, A.; Pini, C. and Vicani, G. (1980): Enzyme linked immuno serbant assay in serodiagnosis of hydatid disease. Am .J. Trop. Med. Hyg., 29 (1) :95-102.

Lowry, O. H.; Rosenbrough, N. J.; Farr, A. L. and Randali, R. J. (1951): Protein measurement with Folinphenol reagent . J. Biol. Chem., 193:265-275.

Langley, R. J. and Hillyer, G. V. (1989): Detection of circulating parasiteantigen in murine fascioliasis by two sites enzyme linked immunosorpent assay. Am. J. Trop. Med. Hyg.,41:472-478

Lombardi, S.; Vegni-Talluri, M.; Banchieri, L. and Esposito, F. (1990): The in vitro adherence of murine eosinophils, neutrophils and non-induced and induced macrophages to infective larvae of Toxocara canis (Nematoda, Ascarididae). Int. J. Parasitol., 20(5):603-613.

Morales, O. L.; López, M. C.; Nicholls, R. S. and Agudel, C. O. (2002): Identification of Toxocara canis antigens by western blot in experimentally infected rabbits. Rev. Inst. Med .Trop. Sao Paulo 44 (4):213-216.

Nicholas, W. L.; Stewart, A. C. and Mitchell, G. F. (1984): Antibody responses to Toxocara canis using sera from parasite-infected mice and protection from toxocariasis by immunisation with ES antigens. Aust. J. Exp. Biol. Med. Sci., 62 ( Pt 5):619-626.
Nunes, C. M.; Tundisi, R. N.; Garcia, J. F.; Heinemann, M. B.; Ogassawara, S. and Richtzenhain, L. J. (1997): Cross-reactions between Toxocara canis and Ascaris suum in the diagnosis of visceral larva migrans by western blotting technique. Rev. Inst. Med. Trop. Sao Paulo, 39(5):253-256.

Parsons, J. C.; Coffman, R. L. and Grieve, R. B. (1993): Antibody to interleukin 5 prevents blood and tissue eosinophilia but not liver trapping in murine larval toxocariasis. Parasite Immunol., 15(9):501-508.

Parsons, J. C. and Grieve, R. B. (1990): Effect of egg dosage and host genotype on liver trapping in murine larval toxocariasis. J. Parasitol., 76(1):53-58.

Rockey, J. H.; John, T.; Donnelly, J. J.; McKenzie, D. F.; Stromberg, B. E. and Soulsby, E. J. (1983): In vitro interaction of eosinophils from ascarid-infected eyes with Ascaris suum and Toxocara canis larvae. Invest Ophthalmol. Vis. Sci., 24 (10): 1346-1357.

Sabry, M. A. (1999): Epidemiological studies on Toxocariasis in animals and man. Ph.D. thesis, Fac. Vet. Med. Cairo Univ. Egypt.

Schantz, P. M. and Glickman, L. T. (1983): Ascaroidios de perros y gatso un problema de Salud Publica y de Medicina Veterinaria. Bol. Ofic. Sanit. Panamer., 94: 571586.

Serrano, F. J.; Reina, D.; Frontera, E.; Roepstorff, A. and Navarrete. A. (2001): Resistance against migrating Ascaris suum larvae in pigs immunized with infective eggs or adult worm antigens. Parasitol., 122(Pt 6):699-707.

Sommerfelt, I. E.; Rosa, A.; Duchene, A. and Degregorio, O.; Lopez, C.; Pisanu, A. and De Torres, R. (2004): Toxocara canis in experimentally infected pigs. Migratory pattern and tissue lesions. Vet. Parasitol., 125: 323-334.

Sugane, K. and Oshima, T. (1983): Trapping of large numbers of larvae in the livers of Toxocara canis-reinfected mice. J. Helminthol., 57(2):95-99.

Taira, K.; Saeed, I.; Permin, A. and Kapel, C. M. (2004): Zoonotic risk of Toxocara canis infection through consumption of pig or poultry viscera. Vet. Parasitol. 121(1-2):115-124.

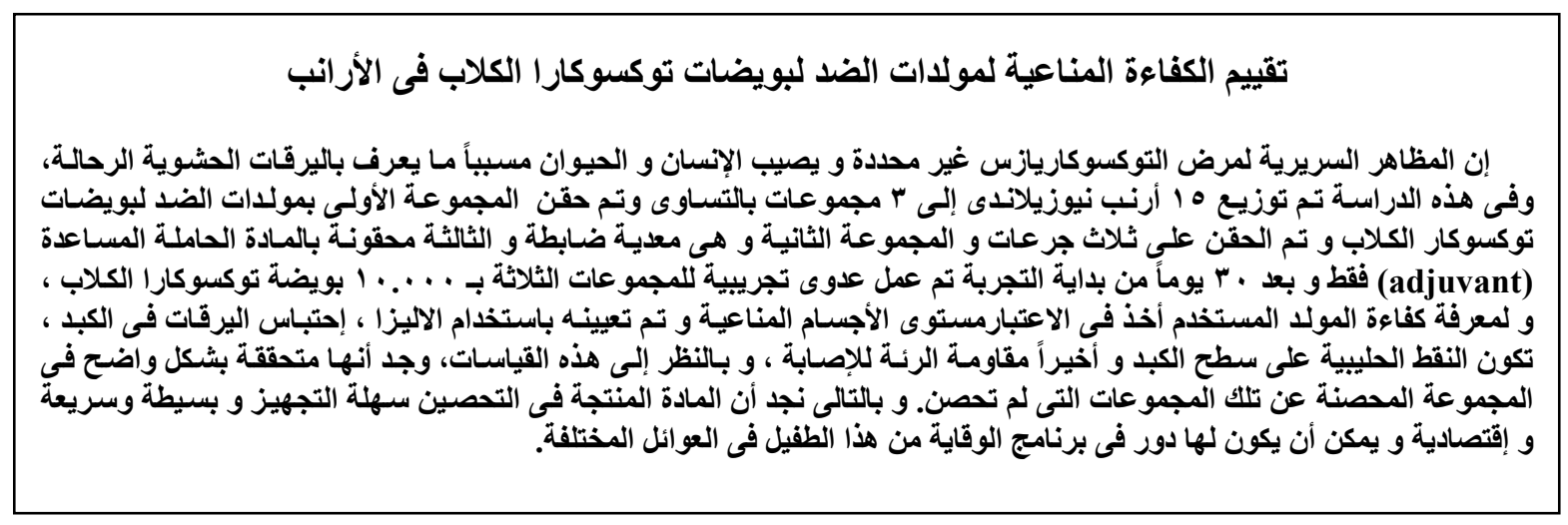

